\title{
Some new fixed point results in partial ordered metric spaces via admissible mappings
}

Wei Long ${ }^{1 *}$, Soomieh Khaleghizadeh ${ }^{2}$, Peyman Salimi ${ }^{3}$, Stojan Radenović ${ }^{4}$ and Satish Shukla ${ }^{5}$

\section{"Correspondence:} hopelw@126.com

${ }^{1}$ College of Mathematics and

Information Science, Jiangxi Normal

University, Nanchang, Jiangxi

330022, People's Republic of China

Full list of author information is

available at the end of the article

\begin{abstract}
The purpose of this paper is to discuss the existence of fixed points for new classes of mappings defined on an ordered metric space. The obtained results generalize and improve some fixed point results in the literature. Some examples show the usefulness of our results.
\end{abstract}

MSC: $46 \mathrm{~N} 40 ; 47 \mathrm{H} 10 ; 54 \mathrm{H} 25 ; 46 \mathrm{~T} 99$

Keywords: partially ordered set; admissible mappings; fixed point

\section{Introduction and preliminaries}

Over the last decades, the fixed point theory has become increasingly useful in the study of nonlinear phenomena. In fact, the fixed point theorems and techniques have been developed in pure and applied analysis, topology and geometry. It is well known that a fundamental result of this theory is Banach's contraction principle [1]. Consequently, in the last 50 years, it has been extensively studied and generalized to many settings; see for example [2-14].

In 2008, Dutta and Choudhury proved the following theorem.

Theorem 1.1 (See [15]) Let $(X, d)$ be a complete metric space and $f: X \rightarrow X$ be such that

$$
\psi(d(f x, f y)) \leq \psi(d(x, y))-\phi(d(x, y)), \quad \forall x, y \in X
$$

where $\psi, \phi:[0,+\infty[\rightarrow[0,+\infty[$ are continuous, non-decreasing, and $\psi(t)=\phi(t)=0$ if and only if $t=0$. Then $f$ has a unique fixed point $x^{*} \in X$.

Note that the above theorem remains true if the hypothesis on $\phi$ is replaced by $\phi$ is lower semi-continuous and $\phi(t)=0$ if and only if $t=0$ (see e.g. [16, 17]).

Eslamian and Abkar stated the following theorem as a generalization of Theorem 1.1.

Theorem 1.2 Let $(X, d)$ be a complete metric space and $f: X \rightarrow X$ be such that

$$
\psi(d(f x, f y)) \leq \alpha(d(x, y))-\beta(d(x, y)), \quad \forall x, y \in X,
$$

@2014 Long et al:; licensee Springer. This is an Open Access article distributed under the terms of the Creative Commons Attribution License (http://creativecommons.org/licenses/by/2.0), which permits unrestricted use, distribution, and reproduction in any medium, provided the original work is properly cited. 
where $\psi, \alpha, \beta:[0,+\infty) \rightarrow[0,+\infty)$ are such that $\psi$ is continuous and non-decreasing, $\alpha$ is continuous and $\beta$ is lower semi-continuous,

$$
\begin{aligned}
& \psi(t)=0 \quad \text { if and only if } \quad t=0, \quad \alpha(0)=\beta(0)=0 \quad \text { and } \\
& \psi(t)-\alpha(t)+\beta(t)>0 \quad \text { for all } t>0 .
\end{aligned}
$$

Then $f$ has a unique fixed point $x^{*} \in X$.

Aydi et al. [18] proved that Theorem 1.2 is a consequence of Theorem 1.1

On the other hand, Ran and Reurings [19] initiate the fixed point theory in the metric spaces equipped with a partial order relation. Let $X$ be a nonempty set equipped with a partial order relation $\preceq$ such that the function $d: X \times X \rightarrow[0, \infty)$ is a metric on $X$, then the triple $(X, d, \preceq)$ is called a partially ordered metric space. Two elements $x, y \in X$ are comparable if either $x \preceq y$ or $y \preceq x$. We write $x \prec y$ if $x \preceq y$ but $x \neq y$. A sequence $\left\{x_{n}\right\}$ in $X$ is said to be non-decreasing with respect to $\preceq$ if $x_{n} \preceq x_{n+1}$ for all $n \in \mathbb{N}$. A mapping $f: X \rightarrow X$ is said to be non-decreasing with respect to $\preceq$ if $x \preceq y$ implies $f x \preceq f y$. In further discussion, if there is no confusion, for the mappings on $X$ and sequences in $X$, we use the phrase 'non-decreasing' instead 'non-decreasing with respect to $\preceq$ '.

Harjani and Sadarangani [20] extended Theorem 1.1 in the framework of partially ordered metric spaces in the following way.

Theorem 1.3 Let $(X, d, \preceq)$ be a partially ordered complete metric space. Let $f: X \rightarrow X$ be a continuous non-decreasing mapping such that

$$
\psi(d(f x, f y)) \leq \psi(d(x, y))-\phi(d(x, y)), \quad \forall x \preceq y,
$$

where $\psi, \phi:[0,+\infty[\rightarrow[0,+\infty[$ are continuous and non-decreasing and $\psi(t)=\phi(t)=0$ if and only if $t=0$. If there exists $x_{0} \in X$ such that $x_{0} \preceq f x_{0}$, then $f$ has a fixed point $x^{*} \in X$.

Choudhury and Kundu [21] generalized Theorems 1.2 and 1.3 as follows.

Theorem 1.4 Let $(X, d, \preceq)$ be a partially ordered complete metric space. Let $f: X \rightarrow X$ be a non-decreasing mapping such that

$$
\psi(d(f x, f y)) \leq \alpha(d(x, y))-\beta(d(x, y)), \quad \forall x \preceq y,
$$

where $\psi, \alpha, \beta:[0,+\infty[\rightarrow[0,+\infty[$ are such that $\psi$ is continuous and non-decreasing, $\alpha$ is continuous, $\beta$ is lower semi-continuous,

$$
\begin{aligned}
& \psi(t)=0 \quad \text { if and only if } t=0, \quad \alpha(0)=\beta(0)=0 \quad \text { and } \\
& \psi(t)-\alpha(t)+\beta(t)>0 \quad \text { for all } t>0 .
\end{aligned}
$$

If there exists $x_{0} \in X$ such that $x_{0} \preceq f x_{0}$, then $f$ has a unique fixed point $x^{*} \in X$.

Aydi et al. [18] proved that Theorem 1.4 is a consequence of Theorem 1.3.

Karapinar and Salimi [22] proved the following theorem as a generalization of Theorems 1.2 and 1.3 where the approach of Aydi et al. [18] cannot be modified for it. 
Theorem 1.5 Let $(X, d, \preceq)$ be an ordered metric space such that $(X, d)$ is complete and let $f: X \rightarrow X$ be a non-decreasing self mappings. Assume that there exist $\psi \in \Psi, \alpha \in \Phi_{\alpha}$, and $\beta \in \Phi_{\beta}$ such that

$$
\psi(t)-\alpha(s)+\beta(s)>0 \quad \text { for all } t>0 \text { and } s=t \text { or } s=0
$$

and

$$
\psi(d(f x, f y)) \leq \alpha(d(x, y))-\beta(d(x, y))
$$

for all comparable $x, y \in X$ where

$$
\begin{aligned}
& \Psi=\{\psi:[0, \infty) \rightarrow[0, \infty) \text { such that } \psi \text { is non-decreasing and lower semicontinuous }\}, \\
& \Phi_{\alpha}=\{\alpha:[0, \infty) \rightarrow[0, \infty) \text { such that } \alpha \text { is upper semicontinuous }\}
\end{aligned}
$$

and

$$
\Phi_{\beta}=\{\beta:[0, \infty) \rightarrow[0, \infty) \text { such that } \beta \text { is lower semicontinuous }\}
$$

\section{Suppose that either}

(a) $f$ is continuous, or

(b) if a non-decreasing sequence $\left\{x_{n}\right\}$ is such that $x_{n} \rightarrow x$, then $x_{n} \preceq x$ for all $n \in \mathbb{N}$.

If there exists $x_{0} \in X$ such that $x_{0} \preceq f x_{0}$, then $f$ has a fixed point.

On the other hand, in 2012, Samet et al. [23] introduced the concepts of $\alpha$ - $\psi$-contractive and $\alpha$-admissible mappings and established various fixed point theorems for such mappings in complete metric spaces. More recently, Salimi et al. [24] modified the notions of $\alpha-\psi$-contractive and $\alpha$-admissible mappings and established fixed point theorems which are proper generalizations of the recent results in [22, 23]. For more on $\alpha$-admissible mappings, see [25-27] and the references therein.

Samet et al. [23] defined the notion of $\alpha$-admissible mappings as follows.

Definition 1.6 Let $T$ be a self-mapping on $X$ and $\alpha: X \times X \rightarrow[0,+\infty)$ be a function. We say that $T$ is an $\alpha$-admissible mapping if

$$
x, y \in X, \quad \alpha(x, y) \geq 1 \quad \Longrightarrow \quad \alpha(T x, T y) \geq 1 .
$$

In [23] the authors consider the family $\Psi$ of non-decreasing functions $\psi:[0,+\infty) \rightarrow$ $[0,+\infty)$ such that $\sum_{n=1}^{+\infty} \psi^{n}(t)<+\infty$ for each $t>0$, where $\psi^{n}$ is the $n$th iterate of $\psi$ and give the following theorem.

Theorem 1.7 Let $(X, d)$ be a complete metric space and $T$ be an $\alpha$-admissible mapping. Assume that

$$
\alpha(x, y) d(T x, T y) \leq \psi(d(x, y))
$$

for all $x, y \in X$, where $\psi \in \Psi$. Also, suppose that the following assertions hold: 
(i) there exists $x_{0} \in X$ such that $\alpha\left(x_{0}, T x_{0}\right) \geq 1$,

(ii) either $T$ is continuous or for any sequence $\left\{x_{n}\right\}$ in $X$ with $\alpha\left(x_{n}, x_{n+1}\right) \geq 1$ for all $n \in \mathbb{N} \cup\{0\}$ and $x_{n} \rightarrow x$ as $n \rightarrow+\infty$, we have $\alpha\left(x_{n}, x\right) \geq 1$ for all $n \in \mathbb{N} \cup\{0\}$.

Then $T$ has a fixed point.

Recently, Hussain et al. [28] obtained the following Geraghty type [29] fixed point theorems via $\alpha$-admissible mappings.

Theorem 1.8 Let $(X, d)$ be a complete metric space and $f: X \rightarrow X$ be an $\alpha$-admissible mapping. Assume that there exists a function $\beta:[0, \infty) \rightarrow[0,1]$ such that for any bounded sequence $\left\{t_{n}\right\}$ of positive reals, $\beta\left(t_{n}\right) \rightarrow 1$ implies $t_{n} \rightarrow 0$ and

$$
(d(f x, f y)+\ell)^{\alpha(x, f x) \alpha(y, f y)} \leq \beta(d(x, y)) d(x, y)+\ell
$$

for all $x, y \in X$ where $\ell \geq 1$. Suppose that either

(a) $f$ is continuous, or

(b) if $\left\{x_{n}\right\}$ is a sequence in $X$ such that $x_{n} \rightarrow x$ and $\alpha\left(x_{n}, x_{n+1}\right) \geq 1$ for all $n$, then $\alpha(x, f x) \geq 1$.

If there exists $x_{0} \in X$ such that $\alpha\left(x_{0}, f x_{0}\right) \geq 1$, then $f$ has a fixed point.

Theorem 1.9 Let $(X, d)$ be a complete metric space and $f: X \rightarrow X$ be an $\alpha$-admissible mapping. Assume that there exists a function $\beta:[0, \infty) \rightarrow[0,1]$ such that for any bounded sequence $\left\{t_{n}\right\}$ of positive reals, $\beta\left(t_{n}\right) \rightarrow 1$ implies $t_{n} \rightarrow 0$ and

$$
(\alpha(x, f x) \alpha(y, f y)+\ell)^{d(f x, f y)} \leq 2^{\beta(d(x, y)) d(x, y)}
$$

for all $x, y \in X$ where $0<\ell \leq 1$. Suppose that either

(a) $f$ is continuous, or

(b) if $\left\{x_{n}\right\}$ is a sequence in $X$ such that $x_{n} \rightarrow x$ and $\alpha\left(x_{n}, x_{n+1}\right) \geq 1$ for all $n$, then $\alpha(x, f x) \geq 1$.

If there exists $x_{0} \in X$ such that $\alpha\left(x_{0}, f x_{0}\right) \geq 1$, then $f$ has a fixed point.

Theorem 1.10 Let $(X, d)$ be a metric space such that $(X, d)$ is complete and $f: X \rightarrow X$ be an $\alpha$-admissible mapping. Assume that there exists a function $\beta:[0, \infty) \rightarrow[0,1]$ such that for any bounded sequence $\left\{t_{n}\right\}$ of positive reals, $\beta\left(t_{n}\right) \rightarrow 1$ implies $t_{n} \rightarrow 0$ and

$$
\alpha(x, f x) \alpha(y, f y) d(f x, f y) \leq \beta(d(x, y)) d(x, y)
$$

for all $x, y \in X$. Suppose that either

(a) $f$ is continuous, or

(b) if $\left\{x_{n}\right\}$ is a sequence in $X$ such that $x_{n} \rightarrow x$ and $\alpha\left(x_{n}, f x_{n}\right) \geq 1$ for all $n$, then $\alpha(x, f x) \geq 1$.

If there exists $x_{0} \in X$ such that $\alpha\left(x_{0}, f x_{0}\right) \geq 1$, then $f$ has a fixed point.

For more details on $\alpha$-admissible mappings and related fixed point results we refer the reader to [30-32].

More recently, Salimi et al. [24] modified and generalized the notions of $\alpha$ - $\psi$-contractive mappings and $\alpha$-admissible mappings by the following ways. 
Definition 1.11 [24] Let $T$ be a self-mapping on $X$ and $\alpha, \eta: X \times X \rightarrow[0,+\infty)$ be two functions. We say that $T$ is an $\alpha$-admissible mapping with respect to $\eta$ if

$$
x, y \in X, \quad \alpha(x, y) \geq \eta(x, y) \quad \Longrightarrow \quad \alpha(T x, T y) \geq \eta(T x, T y) .
$$

Note that if we take $\eta(x, y)=1$ then this definition reduces to Definition 1.6. Also, if we take, $\alpha(x, y)=1$ then we say that $T$ is an $\eta$-subadmissible mapping.

The following result properly contains Theorem 1.7, and Theorems 2.3 and 2.4 of [22].

Theorem 1.12 [24] Let $(X, d)$ be a complete metric space and $T$ be an $\alpha$-admissible mapping with respect to $\eta$. Assume that

$$
x, y \in X, \quad \alpha(x, y) \geq \eta(x, y) \quad \Longrightarrow \quad d(T x, T y) \leq \psi(M(x, y)),
$$

where $\psi \in \Psi$ and

$$
M(x, y)=\max \left\{d(x, y), \frac{d(x, T x)+d(y, T y)}{2}, \frac{d(x, T y)+d(y, T x)}{2}\right\} .
$$

Also, suppose that the following assertions hold:

(i) there exists $x_{0} \in X$ such that $\alpha\left(x_{0}, T x_{0}\right) \geq \eta\left(x_{0}, T x_{0}\right)$,

(ii) either $T$ is continuous or for any sequence $\left\{x_{n}\right\}$ in $X$ with $\alpha\left(x_{n}, x_{n+1}\right) \geq \eta\left(x_{n}, x_{n+1}\right)$ for all $n \in \mathbb{N} \cup\{0\}$ and $x_{n} \rightarrow x$ as $n \rightarrow+\infty$, we have $\alpha\left(x_{n}, x\right) \geq \eta\left(x_{n}, x\right)$ for all $n \in \mathbb{N} \cup\{0\}$.

Then $T$ has a fixed point.

For more details on modified $\alpha-\psi$-contractive mappings and related fixed point results we refer the reader to $[33,34]$.

\section{Main results}

In this section, motivated by the work of Hussain et al. [28] and Salimi et al. [24] we state and prove the following fixed point results in the setting of partially ordered metric spaces.

Theorem 2.1 Let $(X, d, \preceq)$ be a partially ordered metric space such that $(X, d)$ is complete. Assume $f: X \rightarrow X$ and $\gamma: X \times X \rightarrow[0, \infty)$ be two mappings such that $f$ is a non-decreasing and $\gamma$-admissible mapping. Assume that there exist $\psi \in \Psi, \alpha \in \Phi_{\alpha}$, and $\beta \in \Phi_{\beta}$ such that

$$
\psi(t)-\alpha(s)+\beta(s)>0 \quad \text { for all } t>0 \text { and } s=t \text { or } s=0
$$

and

$$
\begin{aligned}
& \gamma(x, f x) \gamma(y, f y) \geq 1 \\
& \quad \Longrightarrow(\psi(d(f x, f y))+\ell)^{\gamma(x, x) \gamma(y, y)} \leq \alpha(d(x, y))-\beta(d(x, y))+\ell
\end{aligned}
$$

for all comparable $x, y \in X$ where $\ell \geq 1$. Suppose that either

(i) $f$ is continuous, or 
(ii) if a non-decreasing sequence $\left\{x_{n}\right\}$ is such that $x_{n} \rightarrow x$ as $n \rightarrow \infty, \gamma\left(x_{n}, f x_{n}\right) \geq 1$, and $\gamma\left(x_{n}, x_{n}\right) \geq 1$ for all $n$, then $\gamma(x, x) \geq 1, \gamma(x, f x) \geq 1$, and $x_{n} \preceq x$ for all $n \in \mathbb{N}$.

If there exists $x_{0} \in X$ such that $\gamma\left(x_{0}, x_{0}\right) \geq 1, \gamma\left(x_{0}, f x_{0}\right) \geq 1$, and $x_{0} \preceq f x_{0}$, then $f$ has a fixed point.

Proof Let $x_{0} \preceq f x_{0}$. We define an iterative sequence $\left\{x_{n}\right\}$ in the following way:

$$
x_{n}=f^{n} x_{0}=f x_{n-1} \quad \text { for all } n \in \mathbb{N} \text {. }
$$

Since $f$ is non-decreasing and $x_{0} \preceq f x_{0}$, we have

$$
x_{0} \preceq x_{1} \preceq x_{2} \preceq \cdots,
$$

and hence $\left\{x_{n}\right\}$ is a non-decreasing sequence. Let $\gamma\left(x_{0}, x_{0}\right) \geq 1$. Since $f$ is a $\gamma$-admissible mapping and $\gamma\left(x_{0}, x_{0}\right) \geq 1$, we deduce that $\gamma\left(x_{1}, x_{1}\right)=\gamma\left(f x_{0}, f x_{0}\right) \geq 1$. By continuing this process, we get $\gamma\left(x_{n}, x_{n}\right) \geq 1$ for all $n \in \mathbb{N} \cup\{0\}$. Also, assume $\gamma\left(x_{0}, f x_{0}\right) \geq 1$. Similarly we get $\gamma\left(x_{n}, f x_{n}\right) \geq 1$ for all $n \in \mathbb{N} \cup\{0\}$. If $x_{n_{0}}=x_{n_{0}+1}=f x_{n_{0}}$ for some $n_{0} \in \mathbb{N}$, then the point $x_{0}$ is the desired fixed point of $f$ which completes the proof. Hence, we suppose that $x_{n} \neq x_{n+1}$, that is, $d\left(x_{n-1}, x_{n}\right)>0$ for all $n$. Hence, (2.3) implies

$$
x_{0} \prec x_{1} \prec x_{2} \prec \cdots .
$$

We want to show that the sequence $\left\{d_{n}:=d\left(x_{n}, x_{n+1}\right)\right\}$ is non-increasing sequence of reals. Suppose, to the contrary, that there exists some $n_{0} \in \mathbb{N}$ such that

$$
d\left(x_{n_{0}-1}, x_{n_{0}}\right) \leq d\left(x_{n_{0}}, x_{n_{0}+1}\right) .
$$

Since $\psi$ is non-decreasing, we obtain

$$
\psi\left(d\left(x_{n_{0}-1}, x_{n_{0}}\right)\right) \leq \psi\left(d\left(x_{n_{0}}, x_{n_{0}+1}\right)\right)
$$

Taking $x=x_{n-1}$ and $y=x_{n}$ in (2.2) we derive

$$
\begin{aligned}
\psi\left(d\left(x_{n}, x_{n+1}\right)\right)+\ell & =\psi\left(d\left(f x_{n-1}, f x_{n}\right)\right)+\ell \\
& \leq\left(\psi\left(d\left(f x_{n-1}, f x_{n}\right)\right)+\ell\right)^{\gamma\left(x_{n-1}, x_{n-1}\right) \gamma\left(x_{n}, x_{n}\right)} \\
& \leq \alpha\left(d\left(x_{n-1}, x_{n}\right)\right)-\beta\left(d\left(x_{n-1}, x_{n}\right)\right)+\ell
\end{aligned}
$$

Hence

$$
\psi\left(d\left(x_{n}, x_{n+1}\right)\right) \leq \alpha\left(d\left(x_{n-1}, x_{n}\right)\right)-\beta\left(d\left(x_{n-1}, x_{n}\right)\right)
$$

for all $n \in \mathbb{N}$. Now, by taking $x=x_{n_{0}-1}$ and $y=x_{n_{0}}$ in (2.7) and applying (2.6) we have

$$
\psi\left(d\left(x_{n_{0}-1}, x_{n_{0}}\right)\right) \leq \alpha\left(d\left(x_{n_{0}-1}, x_{n_{0}}\right)\right)-\beta\left(d\left(x_{n_{0}-1}, x_{n_{0}}\right)\right),
$$

which contradicts (2.12). Therefore, we conclude that $d_{n}<d_{n-1}$ holds for all $n \in \mathbb{N}$. Hence $\left\{d_{n}\right\}$ is a non-increasing sequence of positive real numbers. Thus, there exists $r \geq 0$ such 
that $\lim _{n \rightarrow \infty} d_{n}=r$. We shall show that $r=0$ by method of reductio ad absurdum. For this purpose, we assume that $r>0$. By (2.7) together with the properties of $\alpha, \beta, \psi$ we have

$$
\begin{aligned}
\psi(r) & \leq \liminf _{n \rightarrow \infty} \psi\left(d_{n}\right) \leq \limsup _{n \rightarrow \infty} \psi\left(d_{n}\right) \\
& \leq \limsup _{n \rightarrow \infty}\left[\alpha\left(d_{n-1}\right)-\beta\left(d_{n-1}\right)\right] \leq \alpha(r)-\beta(r),
\end{aligned}
$$

which is a contradiction. Hence

$$
\lim _{n \rightarrow \infty} d_{n}=\lim _{n \rightarrow \infty} d\left(x_{n}, x_{n+1}\right)=0 .
$$

We shall show that the sequence $\left\{x_{n}\right\}$ is a Cauchy sequence. Suppose that it is not. Then there are $\varepsilon>0$ and sequences $m(k)$ and $n(k)$ such that for all positive integers $k$ with $n(k)>$ $m(k)>k$

$$
d\left(x_{n(k)}, x_{m(k)}\right) \geq \varepsilon
$$

Additionally, corresponding to $m(k)$, we may choose $n(k)$ such that it is the smallest integer satisfying (2.9) and $n(k)>m(k) \geq k$. Thus,

$$
d\left(x_{n(k)}, x_{m(k)-1}\right)<\varepsilon
$$

Now, for all $k \in \mathbb{N}$ we have

$$
\varepsilon \leq d\left(x_{n(k)}, x_{m(k)}\right) \leq d\left(x_{n(k)}, x_{m(k)-1}\right)+d\left(x_{m(k)-1}, x_{m(k)}\right)<\varepsilon+d_{m(k)-1} .
$$

So

$$
\lim _{k \rightarrow \infty} d\left(x_{n(k)}, x_{m(k)}\right)=\varepsilon
$$

Again, we have

$$
d\left(x_{n(k)}, x_{m(k)}\right) \leq d\left(x_{m(k)}, x_{m(k)+1}\right)+d\left(x_{m(k)+1}, x_{n(k)+1}\right)+d\left(x_{n(k)+1}, x_{n(k)}\right)
$$

and

$$
d\left(x_{n(k)+1}, x_{m(k)+1}\right) \leq d\left(x_{m(k)}, x_{m(k)+1}\right)+d\left(x_{m(k)}, x_{n(k)}\right)+d\left(x_{n(k)+1}, x_{n(k)}\right) .
$$

By taking the limit as $k \rightarrow+\infty$ in the above inequalities and applying (2.8) and (2.10), we deduce

$$
\lim _{k \rightarrow \infty} d\left(x_{n(k)+1}, x_{m(k)+1}\right)=\varepsilon
$$

Now, from (2.2) with $x=x_{m(k)}$ and $y=x_{n(k)}$ we have

$$
\begin{aligned}
& \psi\left(d\left(x_{m(k)+1}, f x_{n(k)+1}\right)\right)+\ell \\
& \quad \leq\left(\psi\left(d\left(x_{m(k)+1}, f x_{n(k)+1}\right)\right)+\ell\right)^{\gamma\left(x_{m(k)}, x_{m(k)}\right) \gamma\left(x_{n(k)}, x_{n(k)}\right)}
\end{aligned}
$$




$$
\begin{aligned}
& =\left(\psi\left(d\left(f x_{m(k)}, f x_{n(k)}\right)\right)+\ell\right)^{\gamma\left(x_{m(k)}, x_{m(k)}\right) \gamma\left(x_{n(k)}, x_{n(k)}\right)} \\
& \leq \alpha\left(d\left(x_{m(k)}, x_{n(k)}\right)\right)-\beta\left(d\left(x_{m(k)}, x_{n(k)}\right)\right)+\ell .
\end{aligned}
$$

Then

$$
\psi\left(d\left(x_{m(k)+1}, f x_{n(k)+1}\right)\right) \leq \alpha\left(d\left(x_{m(k)}, x_{n(k)}\right)\right)-\beta\left(d\left(x_{m(k)}, x_{n(k)}\right)\right) .
$$

Taking the $\liminf$ as $k \rightarrow+\infty$ in the above inequality, we have

$$
\begin{aligned}
\psi(\varepsilon) & \leq \liminf \psi\left(d\left(x_{n(k)+1}, x_{m(k)+1}\right)\right) \leq \lim \sup \psi\left(d\left(x_{n(k)+1}, x_{m(k)+1}\right)\right) \\
& \leq \lim \sup \left(\alpha\left(d\left(x_{n(k)}, x_{m(k)}\right)\right)-\beta\left(d\left(x_{n(k)}, x_{m(k)}\right)\right)\right) \\
& =\lim \sup \alpha\left(d\left(x_{n(k)}, x_{m(k)}\right)\right)-\liminf \beta\left(d\left(x_{n(k)}, x_{m(k)}\right)\right) \\
& \leq \alpha(\varepsilon)-\beta(\varepsilon) .
\end{aligned}
$$

So we have

$$
\psi(\varepsilon) \leq \alpha(\varepsilon)-\beta(\varepsilon)
$$

which contradicts the fact that $\psi(t)-\alpha(t)+\beta(t)>0$ for all $t>0$. Hence

$$
\lim _{n \rightarrow \infty} d\left(x_{n}, x_{m}\right)=0
$$

that is, the sequence $\left\{x_{n}\right\}$ is a Cauchy sequence. Since $(X, d)$ is complete, then there exists $x^{*} \in X$ such that $x_{n} \rightarrow x^{*}$ as $n \rightarrow \infty$. Suppose that (i) holds. Then

$$
x^{*}=\lim _{n \rightarrow \infty} x_{n+1}=f\left(\lim _{n \rightarrow \infty} x_{n}\right)=f\left(x^{*}\right) \text {. }
$$

Hence, $x^{*}$ is a fixed point of $f$. Suppose that (ii) holds, that is, $\gamma\left(x^{*}, x^{*}\right) \geq 1, \gamma\left(x^{*}, f x^{*}\right) \geq 1$, and $x_{n} \preceq x^{*}$ for all $n \geq 0$. We claim that $x^{*}$ is a fixed point of $f$, that is, $\lim _{n \rightarrow \infty} d\left(x_{n+1}\right.$, $\left.f x^{*}\right)=0$. Suppose, to the contrary, that $\lim _{n \rightarrow \infty} d\left(x_{n+1}, f x^{*}\right)=d\left(x^{*}, f x^{*}\right)>0$. Due to condition (2.2), we have

$$
\begin{aligned}
\psi\left(d\left(f x^{*}, x_{n+1}\right)\right)+\ell & =\psi\left(d\left(f x^{*}, f x_{n}\right)\right)+\ell \\
& \leq\left(\psi\left(d\left(f x^{*}, f x_{n}\right)\right)+\ell\right)^{\gamma\left(x^{*}, x^{*}\right) \gamma\left(x_{n}, x_{n}\right)} \\
& \leq \alpha\left(d\left(x^{*}, x_{n}\right)\right)-\beta\left(d\left(x^{*}, x_{n}\right)\right)+\ell
\end{aligned}
$$

Taking the liminf as $n \rightarrow \infty$ in the above inequality, we obtain

$$
\begin{aligned}
\psi\left(d\left(x^{*}, f x^{*}\right)\right) & \leq \liminf _{n \rightarrow \infty} \psi\left(d\left(x_{n+1}, f x^{*}\right)\right) \\
& =\liminf _{n \rightarrow \infty} \psi\left(d\left(f x_{n}, f x^{*}\right)\right) \leq \limsup _{n \rightarrow \infty} \psi\left(d\left(x_{n}, f x^{*}\right)\right) \\
& \leq \limsup _{n \rightarrow \infty}\left(\alpha\left(d\left(x_{n}, x^{*}\right)\right)-\beta\left(d\left(x_{n}, x^{*}\right)\right)\right) \\
& \leq \alpha(0)-\beta(0),
\end{aligned}
$$

which is a contradiction. Hence $\lim _{n \rightarrow \infty} d\left(x_{n+1}, f x^{*}\right)=d\left(x^{*}, f x^{*}\right)=0$ and so, $x^{*}=f x^{*}$. 
Example 2.2 Let $X=[0, \infty)$ be endowed with the usual metric $d(x, y)=|x-y|$ for all $x, y \in X$ and $f: X \rightarrow X$ be defined by

$$
f x= \begin{cases}\frac{x}{2(x+1)} & \text { if } x \in[0,1], \\ 3 x^{2} & \text { if } x \in(1, \infty) .\end{cases}
$$

Define also $\gamma: X \times X \rightarrow[0,+\infty), \psi:[0,+\infty) \rightarrow[0,+\infty), \alpha:[0,+\infty) \rightarrow[0,+\infty)$, and $\beta:$ $[0,+\infty) \rightarrow[0,+\infty)$ by

$$
\begin{aligned}
& \gamma(x, y)=\left\{\begin{array}{ll}
1 & \text { if } x, y \in[0,1], \\
0 & \text { otherwise, }
\end{array} \quad \psi(t)=t+1 / 2,\right. \\
& \alpha(t)=t+1 \text { and } \beta(t)=t / 2+1 / 2 .
\end{aligned}
$$

We prove that Theorem 2.1 can be applied to $f$. But Theorem 1.5 cannot be applied.

Clearly, $(X, d)$ is a complete metric space. We show that $f$ is a $\gamma$-admissible mapping. Let $x, y \in X$. If $\gamma(x, y) \geq 1$ then $x, y \in[0,1]$. On the other hand, for all $x \in[0,1]$ we have $f x \leq 1$. It follows that $\gamma(f x, f y) \geq 1$. Thus the assertion holds. Because of the above arguments, $\gamma(0,0) \geq 1$. Now, if $\left\{x_{n}\right\}$ is a sequence in $X$ such that $\gamma\left(x_{n}, x_{n}\right) \geq 1$ for all $n \in \mathbb{N} \cup\{0\}$ and $x_{n} \rightarrow x$ as $n \rightarrow+\infty$, then $\left\{x_{n}\right\} \subset[0,1]$ and hence $x \in[0,1]$. This implies that $\gamma(x, x) \geq 1$. Also $\psi(t)=t+1 / 2>t / 2+1 / 2=\alpha(t)-\beta(t)$ and $\psi(t)=t+1 / 2>1 / 2=\alpha(0)-\beta(0)$ for all $t>0$. Let $\gamma(x, f x) \gamma(y, f y) \geq 1$. Then $x, y \in[0,1]$. Indeed, if $x \notin[0,1]$ or $y \notin[0,1]$. So, $\gamma(x, f x)=0$ or $\gamma(y, f y)$. That is, $\gamma(x, f x) \gamma(y, f y)=0<1$ which is a contradiction. Without any loss of generality we assume that $y \geq x$. We get

$$
\begin{aligned}
(\psi(d(f x, f y))+\ell)^{\gamma(x, x) \gamma(y, y)} & =f y-f x+1 / 2+\ell \\
& =\frac{y}{2(y+1)}-\frac{x}{2(x+1)}+1 / 2+\ell \\
& =\frac{y-x}{2(1+x)(1+y)}+1 / 2+\ell \\
& \leq \frac{y-x}{2}+1 / 2+\ell \\
& =\alpha(d(x, y))-\beta(d(x, y))+\ell .
\end{aligned}
$$

Then the condition of Theorem 2.1 holds and $f$ has a fixed point. Let $x=2$ and $y=3$, then

$$
\psi(d(f 2, f 3))=15+1 / 2>1=\alpha(d(2,3))-\beta(d(2,3)) .
$$

That is, the contractive condition of Theorem 1.5 does not hold for this example.

Corollary 2.3 Let $(X, d, \preceq)$ be a partially ordered metric space such that $(X, d)$ is complete. Assume $f: X \rightarrow X$ and $\gamma: X \times X \rightarrow[0, \infty)$ be two mappings such that $f$ is a non-decreasing $\gamma$-admissible mapping. Assume that there exist $\psi \in \Psi, \alpha \in \Phi_{\alpha}$, and $\beta \in \Phi_{\beta}$ such that

$$
\psi(t)-\alpha(s)+\beta(s)>0 \quad \text { for all } t>0 \text { and } s=\text { tor } s=0 .
$$


(i) $f$ is continuous, or

(ii) if a non-decreasing sequence $\left\{x_{n}\right\}$ is such that $x_{n} \rightarrow x$ as $n \rightarrow \infty, \gamma\left(x_{n}, f x_{n}\right) \geq 1$, and $\gamma\left(x_{n}, x_{n}\right) \geq 1$ for all $n$, then $\gamma(x, x) \geq 1, \gamma(x, f x) \geq 1$, and $x_{n} \preceq x$ for all $n \in \mathbb{N}$,

(iii)

$$
\gamma(x, f x) \gamma(y, f y)(\psi(d(f x, f y))+\ell)^{\gamma(x, x) \gamma(y, y)} \leq \alpha(d(x, y))-\beta(d(x, y))+\ell
$$

for all comparable $x, y \in X$ where $\ell \geq 1$.

If there exists $x_{0} \in X$ such that $\gamma\left(x_{0}, x_{0}\right) \geq 1, \gamma\left(x_{0}, f x_{0}\right) \geq 1$, and $x_{0} \preceq f x_{0}$, then $f$ has $a$ fixed point.

Proof Let $\gamma(x, f x) \gamma(y, f y) \geq 1$. Then from (iii) we have

$$
\begin{aligned}
(\psi(d(f x, f y))+\ell)^{\gamma(x, x) \gamma(y, y)} & \leq \gamma(x, f x) \gamma(y, f y)(\psi(d(f x, f y))+\ell)^{\gamma(x, x) \gamma(y, y)} \\
& \leq \alpha(d(x, y))-\beta(d(x, y))+\ell .
\end{aligned}
$$

That is,

$$
\begin{aligned}
& \gamma(x, f x) \gamma(y, f y) \geq 1 \\
& \quad \Longrightarrow \quad(\psi(d(f x, f y))+\ell)^{\gamma(x, x) \gamma(y, y)} \leq \alpha(d(x, y))-\beta(d(x, y))+\ell .
\end{aligned}
$$

Hence, all conditions of Theorem 2.1 hold and $f$ has a fixed point.

Now, we prove our second main result as follows.

Theorem 2.4 Let $(X, d, \preceq)$ be a partially ordered metric space such that $(X, d)$ is complete. Assume $f: X \rightarrow X$ and $\gamma: X \times X \rightarrow[0, \infty)$ are two mappings such that $f$ is a nondecreasing $\gamma$-admissible mapping. Assume that there exist $\psi \in \Psi, \alpha \in \Phi_{\alpha}$, and $\beta \in \Phi_{\beta}$ such that

$$
\psi(t)-\alpha(s)+\beta(s)>0 \quad \text { for all } t>0 \text { and } s=t \text { or } s=0
$$

and

$$
\begin{aligned}
& \gamma(x, f x) \gamma(y, f y) \geq 1 \\
& \quad \Longrightarrow(\gamma(x, x) \gamma(y, y)+1)^{\psi(d(f x, f y))} \leq 2^{\alpha(d(x, y))-\beta(d(x, y))}
\end{aligned}
$$

for all comparable $x, y \in X$. Suppose that either

(i) $f$ is continuous, or

(ii) if a non-decreasing sequence $\left\{x_{n}\right\}$ is such that $x_{n} \rightarrow x$ as $n \rightarrow \infty, \gamma\left(x_{n}, x_{n}\right) \geq 1$, and $\gamma\left(x_{n}, f x_{n}\right) \geq 1$ for all $n$, then $\gamma(x, x) \geq 1, \gamma(x, f x) \geq 1$, and $x_{n} \preceq x$ for all $n \in \mathbb{N}$.

If there exists $x_{0} \in X$ such that $\alpha\left(x_{0}, x_{0}\right) \geq 1, \alpha\left(x_{0}, f x_{0}\right) \geq 1$, and $x_{0} \preceq f x_{0}$, then $f$ has a fixed point.

Proof Let $x_{0} \preceq f x_{0}$. We define an iterative sequence $\left\{x_{n}\right\}$ in the following way:

$$
x_{n}=f^{n} x_{0}=f x_{n-1} \quad \text { for all } n \in \mathbb{N} \text {. }
$$


From Theorem 2.1 we know that $\left\{x_{n}\right\}$ is a non-decreasing sequence, $\gamma\left(x_{n}, x_{n}\right) \geq 1$ and $\gamma\left(x_{n}, f x_{n}\right) \geq 1$ for all $n \in \mathbb{N} \cup\{0\}$. Also, similarly, we suppose that $d\left(x_{n-1}, x_{n}\right)>0$ for all $n$. We shall show that the sequence $\left\{d_{n}:=d\left(x_{n}, x_{n+1}\right)\right\}$ is non-increasing sequence of reals. Assume that there exists some $n_{0} \in \mathbb{N}$ such that

$$
d\left(x_{n_{0}-1}, x_{n_{0}}\right) \leq d\left(x_{n_{0}}, x_{n_{0}+1}\right) .
$$

Hence

$$
\psi\left(d\left(x_{n_{0}-1}, x_{n_{0}}\right)\right) \leq \psi\left(d\left(x_{n_{0}}, x_{n_{0}+1}\right)\right)
$$

Taking $x=x_{n-1}$ and $y=x_{n}$ in (2.13) and applying (2.6) we get

$$
\begin{aligned}
2^{\psi\left(d\left(x_{n}, x_{n+1}\right)\right)} & =2^{\psi\left(d\left(f x_{n-1}, f x_{n}\right)\right)} \\
& \leq\left(\gamma\left(x_{n-1}, x_{n-1}\right) \gamma\left(x_{n}, x_{n}\right)+1\right)^{\psi\left(d\left(f x_{n-1}, f x_{n}\right)\right)} \\
& \leq 2^{\alpha\left(d\left(x_{n-1}, x_{n}\right)\right)-\beta\left(d\left(x_{n-1}, x_{n}\right)\right)} .
\end{aligned}
$$

Hence

$$
\psi\left(d\left(x_{n}, x_{n+1}\right)\right) \leq \alpha\left(d\left(x_{n-1}, x_{n}\right)\right)-\beta\left(d\left(x_{n-1}, x_{n}\right)\right)
$$

for all $n \in \mathbb{N}$. Now, by taking $x=x_{n_{0}-1}$ and $y=x_{n_{0}}$ in (2.15) and using (2.14) we deduce

$$
\psi\left(d\left(x_{n_{0}-1}, x_{n_{0}}\right)\right) \leq \alpha\left(d\left(x_{n_{0}-1}, x_{n_{0}}\right)\right)-\beta\left(d\left(x_{n_{0}-1}, x_{n_{0}}\right)\right),
$$

which is a contradiction. Then $d_{n}<d_{n-1}$ holds for all $n \in \mathbb{N}$ and so there exists $r \geq 0$ such that $\lim _{n \rightarrow \infty} d_{n}=r$. Reviewing the proof of Theorem 2.1 we can show that $r=0$. Now, suppose, to the contrary, that $\left\{x_{n}\right\}$ is not a Cauchy sequence. Then there exist $\varepsilon>0$ and sequences $m(k)$ and $n(k)$ such that for all positive integers $k$ with $n(k)>m(k)>k$

$$
\lim _{k \rightarrow \infty} d\left(x_{n(k)}, x_{m(k)}\right)=\varepsilon
$$

and

$$
\lim _{k \rightarrow \infty} d\left(x_{n(k)+1}, x_{m(k)+1}\right)=\varepsilon
$$

By (2.13) with $x=x_{m(k)}$ and $y=x_{n(k)}$ we have

$$
\begin{aligned}
& 2^{\psi\left(d\left(x_{m(k)+1}, f x_{n(k)+1}\right)\right)} \\
& \quad \leq\left(\gamma\left(x_{m(k)}, x_{m(k)}\right) \gamma\left(x_{n(k)}, x_{n(k)}\right)+1\right)^{\psi\left(d\left(x_{m(k)+1}, f x_{n(k)+1}\right)\right)} \\
& \quad=\left(\gamma\left(x_{m(k)}, x_{m(k)}\right) \gamma\left(x_{n(k)}, x_{n(k)}\right)+1\right)^{\psi\left(d\left(f x_{m(k)}, f x_{n(k)}\right)\right)} \\
& \quad \leq 2^{\alpha\left(d\left(x_{m(k)}, x_{n(k)}\right)\right)-\beta\left(d\left(x_{m(k)}, x_{n(k)}\right)\right)}
\end{aligned}
$$

and so

$$
\psi\left(d\left(x_{m(k)+1}, f x_{n(k)+1}\right)\right) \leq \alpha\left(d\left(x_{m(k)}, x_{n(k)}\right)\right)-\beta\left(d\left(x_{m(k)}, x_{n(k)}\right)\right) .
$$


By taking the liminf as $k \rightarrow+\infty$ in the above inequality, we have

$$
\begin{aligned}
\psi(\varepsilon) & \leq \liminf \psi\left(d\left(x_{n(k)+1}, x_{m(k)+1}\right)\right) \leq \lim \sup \psi\left(d\left(x_{n(k)+1}, x_{m(k)+1}\right)\right) \\
& \leq \lim \sup \left(\alpha\left(d\left(x_{n(k)}, x_{m(k)}\right)\right)-\beta\left(d\left(x_{n(k)}, x_{m(k)}\right)\right)\right) \\
& =\lim \sup \alpha\left(d\left(x_{n(k)}, x_{m(k)}\right)\right)-\liminf \beta\left(d\left(x_{n(k)}, x_{m(k)}\right)\right) \\
& \leq \alpha(\varepsilon)-\beta(\varepsilon) .
\end{aligned}
$$

Therefore

$$
\psi(\varepsilon) \leq \alpha(\varepsilon)-\beta(\varepsilon)
$$

which is a contradiction. Hence,

$$
\lim _{n \rightarrow \infty} d\left(x_{n}, x_{m}\right)=0
$$

Then $\left\{x_{n}\right\}$ is a Cauchy sequence. Since $(X, d)$ is complete, there exists $x^{*} \in X$ such that $x_{n} \rightarrow x^{*}$ as $n \rightarrow \infty$. Let (i) hold. Then

$$
x^{*}=\lim _{n \rightarrow \infty} x_{n+1}=f\left(\lim _{n \rightarrow \infty} x_{n}\right)=f\left(x^{*}\right) .
$$

So, $x^{*}$ is a fixed point of $f$. Now, we assume that (ii) holds, that is, $\gamma\left(x^{*}, x^{*}\right) \geq 1$, $\gamma\left(x^{*}, f x^{*}\right) \geq 1$, and $x_{n} \preceq x^{*}$ for all $n \geq 0$. We claim that $x^{*}$ is a fixed point of $f$, equivalently, $\lim _{n \rightarrow \infty} d\left(x_{n+1}, f x^{*}\right)=0$. Suppose, to the contrary, that $\lim _{n \rightarrow \infty} d\left(x_{n+1}, f x^{*}\right)=d\left(x^{*}, f x^{*}\right)>0$.

From (2.13), we have

$$
\begin{aligned}
2^{\psi\left(d\left(f x^{*}, x_{n+1}\right)\right)} & =2^{\psi\left(d\left(f x^{*}, f x_{n}\right)\right)} \\
& \leq\left(\gamma\left(x^{*}, x^{*}\right) \gamma\left(x_{n}, x_{n}\right)+1\right)^{\psi\left(d\left(f x^{*}, f x_{n}\right)\right)} \\
& \leq 2^{\alpha\left(d\left(x^{*}, x_{n}\right)\right)-\beta\left(d\left(x^{*}, x_{n}\right)\right) .}
\end{aligned}
$$

Taking the $\liminf$ as $n \rightarrow \infty$ in the above inequality, we obtain

$$
\begin{aligned}
\psi\left(d\left(x^{*}, f x^{*}\right)\right) & \leq \liminf _{n \rightarrow \infty} \psi\left(d\left(x_{n+1}, f x^{*}\right)\right) \\
& =\liminf _{n \rightarrow \infty} \psi\left(d\left(f x_{n}, f x^{*}\right)\right) \leq \limsup _{n \rightarrow \infty} \psi\left(d\left(x_{n}, f x^{*}\right)\right) \\
& \leq \limsup _{n \rightarrow \infty}\left(\alpha\left(d\left(x_{n}, x^{*}\right)\right)-\beta\left(d\left(x_{n}, x^{*}\right)\right)\right) \\
& \leq \alpha(0)-\beta(0),
\end{aligned}
$$

which is a contradiction. Then $\lim _{n \rightarrow \infty} d\left(x_{n+1}, f x^{*}\right)=d\left(x^{*}, f x^{*}\right)=0$ and hence, $x^{*}=f x^{*}$.

Example 2.5 Let $X$ and $d$ be as in Example 2.2. Define $f: X \rightarrow X$ by

$$
f x= \begin{cases}\frac{1}{4}\left(1-x^{2}\right) & \text { if } x \in[0,1] \\ e^{x} & \text { if } x \in(1, \infty)\end{cases}
$$


Define also $\gamma, \psi, \alpha$, and $\beta$ as in Example 2.2. We shall show that Theorem 2.4 can be applied to $f$, but Theorem 1.5 cannot be applied. Proceeding as in the proof of Example 2.2 $f$ is a $\gamma$-admissible mapping, $\alpha(0,0) \geq 1$, and if $\left\{x_{n}\right\}$ is a sequence in $X$ such that $\alpha\left(x_{n}, x_{n}\right) \geq$ 1 for all $n \in \mathbb{N} \cup\{0\}$ and $x_{n} \rightarrow x$ as $n \rightarrow+\infty$, then $\gamma(x, x) \geq 1$. Let $\gamma(x, f x) \gamma(y, f y) \geq 1$. Then $x, y \in[0,1]$. Assume $y \geq x$. We get

$$
\begin{aligned}
(\gamma(x, x) \gamma(y, y)+1)^{\psi(d(f x, f y))} & =2^{f x-f y+1 / 2} \\
& =2^{\left[\frac{1}{4}\left(y^{2}-x^{2}\right)+1 / 2\right]} \\
& =2^{\left[\frac{1}{4}(y+x)(y-x)+1 / 2\right]} \\
& \leq 2^{\left[\frac{1}{2}(y-x)+1 / 2\right]} \\
& =2^{\alpha(d(x, y))-\beta(d(x, y))} .
\end{aligned}
$$

Then the condition of Theorem 2.4 holds and so $f$ has a fixed point. Let $x=\ln 2$ and $y=\ln 4$, then

$$
\begin{aligned}
\psi(d(f(\ln 2), f(\ln 4))) & =2+1 / 2>\frac{1}{2} \ln 2+1 / 2 \\
& =\alpha(d(\ln 2, \ln 4))-\beta(d(\ln 2, \ln 4)) .
\end{aligned}
$$

Hence, the condition of Theorem 1.5 does not hold for this example.

Corollary 2.6 Let $(X, d, \preceq)$ be a partially ordered metric space such that $(X, d)$ is complete. Assume $f: X \rightarrow X$ and $\gamma: X \times X \rightarrow[0, \infty)$ are two mappings such that $f$ is a nondecreasing $\gamma$-admissible mapping. Assume that there exist $\psi \in \Psi, \alpha \in \Phi_{\alpha}$, and $\beta \in \Phi_{\beta}$ such that

$$
\psi(t)-\alpha(s)+\beta(s)>0 \quad \text { for all } t>0 \text { and } s=t \text { or } s=0
$$

and

$$
\gamma(x, f x) \gamma(y, f y)(\gamma(x, x) \gamma(y, y)+1)^{\psi(d(f x, f y))} \leq 2^{\alpha(d(x, y))-\beta(d(x, y))}
$$

for all comparable $x, y \in X$. Suppose that either

(i) $f$ is continuous, or

(ii) if a non-decreasing sequence $\left\{x_{n}\right\}$ is such that $x_{n} \rightarrow x$ as $n \rightarrow \infty, \gamma\left(x_{n}, x_{n}\right) \geq 1$, and $\gamma\left(x_{n}, f x_{n}\right) \geq 1$ for all $n$, then $\gamma(x, x) \geq 1, \gamma(x, f x) \geq 1$, and $x_{n} \preceq x$ for all $n \in \mathbb{N}$.

If there exists $x_{0} \in X$ such that $\alpha\left(x_{0}, x_{0}\right) \geq 1, \alpha\left(x_{0}, f x_{0}\right) \geq 1$, and $x_{0} \preceq f x_{0}$, then $f$ has $a$ fixed point.

Theorem 2.7 Let $(X, d, \preceq)$ be a partially ordered metric space such that $(X, d)$ is complete. Assume that $f: X \rightarrow X$ and $\gamma: X \times X \rightarrow[0, \infty)$ are two mappings such that $f$ is a nondecreasing $\gamma$-admissible mapping. Assume that there exist $\psi \in \Psi, \alpha \in \Phi_{\alpha}$, and $\beta \in \Phi_{\beta}$ such that

$$
\psi(t)-\alpha(s)+\beta(s)>0 \quad \text { for all } t>0 \text { and } s=t \text { or } s=0
$$


and

$$
\begin{aligned}
& \gamma(x, f x) \gamma(y, f y) \geq 1 \\
& \quad \Longrightarrow \quad \gamma(x, x) \gamma(y, y) \psi(d(f x, f y)) \leq \alpha(d(x, y))-\beta(d(x, y))
\end{aligned}
$$

for all comparable $x, y \in X$. Suppose that either

(i) $f$ is continuous, or

(ii) if a non-decreasing sequence $\left\{x_{n}\right\}$ is such that $x_{n} \rightarrow x$ as $n \rightarrow \infty, \gamma\left(x_{n}, x_{n}\right) \geq 1$, and $\gamma\left(x_{n}, f x_{n}\right) \geq 1$ for all $n$, then $\gamma(x, x) \geq 1, \gamma(x, f x) \geq 1$, and $x_{n} \preceq x$ for all $n \in \mathbb{N}$.

If there exists $x_{0} \in X$ such that $\alpha\left(x_{0}, x_{0}\right) \geq 1, \alpha\left(x_{0}, f x_{0}\right) \geq 1$, and $x_{0} \preceq f x_{0}$, then $f$ has $a$ fixed point.

Proof Let $x_{0} \preceq f x_{0}$. We define an iterative sequence $\left\{x_{n}\right\}$ in the following way:

$$
x_{n}=f^{n} x_{0}=f x_{n-1} \quad \text { for all } n \in \mathbb{N} \text {. }
$$

From Theorem 2.1 we know that $\left\{x_{n}\right\}$ is a non-decreasing sequence, $\gamma\left(x_{n}, x_{n}\right) \geq 1$, and $\gamma\left(x_{n}, f x_{n}\right) \geq 1$ for all $n \in \mathbb{N} \cup\{0\}$. Also, similarly, we suppose that $d\left(x_{n-1}, x_{n}\right)>0$ for all $n$. We shall show that the sequence $\left\{d_{n}:=d\left(x_{n}, x_{n+1}\right)\right\}$ is non-increasing. Assume that there exists some $n_{0} \in \mathbb{N}$ such that

$$
d\left(x_{n_{0}-1}, x_{n_{0}}\right) \leq d\left(x_{n_{0}}, x_{n_{0}+1}\right) .
$$

Hence

$$
\psi\left(d\left(x_{n_{0}-1}, x_{n_{0}}\right)\right) \leq \psi\left(d\left(x_{n_{0}}, x_{n_{0}+1}\right)\right)
$$

Taking $x=x_{n-1}$ and $y=x_{n}$ in (2.18) and applying (2.19) we get

$$
\begin{aligned}
\psi\left(d\left(x_{n}, x_{n+1}\right)\right) & =\psi\left(d\left(f x_{n-1}, f x_{n}\right)\right) \\
& \leq \gamma\left(x_{n-1}, x_{n-1}\right) \gamma\left(x_{n}, x_{n}\right) \psi\left(d\left(f x_{n-1}, f x_{n}\right)\right) \\
& \leq \alpha\left(d\left(x_{n-1}, x_{n}\right)\right)-\beta\left(d\left(x_{n-1}, x_{n}\right)\right) .
\end{aligned}
$$

Hence

$$
\psi\left(d\left(x_{n}, x_{n+1}\right)\right) \leq \alpha\left(d\left(x_{n-1}, x_{n}\right)\right)-\beta\left(d\left(x_{n-1}, x_{n}\right)\right)
$$

for all $n \in \mathbb{N}$. Now, by taking $x=x_{n_{0}-1}$ and $y=x_{n_{0}}$ in (2.20) and using (2.19) we deduce

$$
\psi\left(d\left(x_{n_{0}-1}, x_{n_{0}}\right)\right) \leq \alpha\left(d\left(x_{n_{0}-1}, x_{n_{0}}\right)\right)-\beta\left(d\left(x_{n_{0}-1}, x_{n_{0}}\right)\right),
$$

which is a contradiction. Then $d_{n}<d_{n-1}$ holds for all $n \in \mathbb{N}$ and so there exists $r \geq 0$ such that $\lim _{n \rightarrow \infty} d_{n}=r$. Proceeding as in the proof of Theorem 2.1 we conclude that $r=0$. Now, suppose, to the contrary that $\left\{x_{n}\right\}$ is not a Cauchy sequence. Then there exist $\varepsilon>0$ and sequences $m(k)$ and $n(k)$ such that for all positive integers $k$ with $n(k)>m(k)>k$

$$
\lim _{k \rightarrow \infty} d\left(x_{n(k)}, x_{m(k)}\right)=\varepsilon
$$


and

$$
\lim _{k \rightarrow \infty} d\left(x_{n(k)+1}, x_{m(k)+1}\right)=\varepsilon
$$

By (2.18) with $x=x_{m(k)}$ and $y=x_{n(k)}$ we have

$$
\begin{aligned}
\psi & \left(d\left(x_{m(k)+1}, f x_{n(k)+1}\right)\right) \\
& \leq \gamma\left(x_{m(k)}, x_{m(k)}\right) \gamma\left(x_{n(k)}, x_{n(k)}\right) \psi\left(d\left(x_{m(k)+1}, f x_{n(k)+1}\right)\right) \\
& =\gamma\left(x_{m(k)}, x_{m(k)}\right) \gamma\left(x_{n(k)}, x_{n(k)}\right) \psi\left(d\left(f x_{m(k)}, f x_{n(k)}\right)\right) \\
& \leq \alpha\left(d\left(x_{m(k)}, x_{n(k)}\right)\right)-\beta\left(d\left(x_{m(k)}, x_{n(k)}\right)\right)
\end{aligned}
$$

and so

$$
\psi\left(d\left(x_{m(k)+1}, f x_{n(k)+1}\right)\right) \leq \alpha\left(d\left(x_{m(k)}, x_{n(k)}\right)\right)-\beta\left(d\left(x_{m(k)}, x_{n(k)}\right)\right) .
$$

Taking the liminf as $k \rightarrow+\infty$ in the above inequality, we have

$$
\begin{aligned}
\psi(\varepsilon) & \leq \liminf \psi\left(d\left(x_{n(k)+1}, x_{m(k)+1}\right)\right) \leq \lim \sup \psi\left(d\left(x_{n(k)+1}, x_{m(k)+1}\right)\right) \\
& \leq \lim \sup \left(\alpha\left(d\left(x_{n(k)}, x_{m(k)}\right)\right)-\beta\left(d\left(x_{n(k)}, x_{m(k)}\right)\right)\right) \\
& =\lim \sup \alpha\left(d\left(x_{n(k)}, x_{m(k)}\right)\right)-\liminf \beta\left(d\left(x_{n(k)}, x_{m(k)}\right)\right) \\
& \leq \alpha(\varepsilon)-\beta(\varepsilon) .
\end{aligned}
$$

Therefore

$$
\psi(\varepsilon) \leq \alpha(\varepsilon)-\beta(\varepsilon)
$$

which is a contradiction. Hence

$$
\lim _{n \rightarrow \infty} d\left(x_{n}, x_{m}\right)=0
$$

that is, $\left\{x_{n}\right\}$ is a Cauchy sequence. Since $(X, d)$ is complete, there exists $x^{*} \in X$ such that $x_{n} \rightarrow x^{*}$ as $n \rightarrow \infty$. Let (i) hold. Then

$$
x^{*}=\lim _{n \rightarrow \infty} x_{n+1}=f\left(\lim _{n \rightarrow \infty} x_{n}\right)=f\left(x^{*}\right) .
$$

So, $x^{*}$ is a fixed point of $f$. Now, we assume that (ii) holds, that is, $\gamma\left(x^{*}, x^{*}\right) \geq 1, \gamma\left(x^{*}, f x^{*}\right) \geq$ 1 , and $x_{n} \preceq x^{*}$ for all $n \geq 0$. We claim that $x^{*}$ is a fixed point of $f$, or equivalently, $\lim _{n \rightarrow \infty} d\left(x_{n+1}, f x^{*}\right)=0$. Suppose, to the contrary, that $\lim _{n \rightarrow \infty} d\left(x_{n+1}, f x^{*}\right)=d\left(x^{*}, f x^{*}\right)>0$. From (2.18), we have

$$
\begin{aligned}
\psi\left(d\left(f x^{*}, x_{n+1}\right)\right) & =\psi\left(d\left(f x^{*}, f x_{n}\right)\right) \\
& \leq \gamma\left(x^{*}, x^{*}\right) \gamma\left(x_{n}, x_{n}\right) \psi\left(d\left(f x^{*}, f x_{n}\right)\right) \\
& \leq \alpha\left(d\left(x^{*}, x_{n}\right)\right)-\beta\left(d\left(x^{*}, x_{n}\right)\right) .
\end{aligned}
$$


Taking the $\liminf$ as $n \rightarrow \infty$ in the above inequality, we obtain

$$
\begin{aligned}
\psi\left(d\left(x^{*}, f x^{*}\right)\right) & \leq \liminf _{n \rightarrow \infty} \psi\left(d\left(x_{n+1}, f x^{*}\right)\right) \\
& =\liminf _{n \rightarrow \infty} \psi\left(d\left(f x_{n}, f x^{*}\right)\right) \leq \limsup _{n \rightarrow \infty} \psi\left(d\left(x_{n}, f x^{*}\right)\right) \\
& \leq \limsup _{n \rightarrow \infty}\left(\alpha\left(d\left(x_{n}, x^{*}\right)\right)-\beta\left(d\left(x_{n}, x^{*}\right)\right)\right) \\
& \leq \alpha(0)-\beta(0),
\end{aligned}
$$

which is a contradiction. Then $\lim _{n \rightarrow \infty} d\left(x_{n+1}, f x^{*}\right)=d\left(x^{*}, f x^{*}\right)=0$, and hence $x^{*}=f x^{*}$.

Example 2.8 Let $X$ and $d$ be as in Example 2.2. Define $f: X \rightarrow X$ by

$$
f x= \begin{cases}\frac{1}{8} x^{4} & \text { if } x \in[0,1], \\ e^{\sin x}+x & \text { if } x \in(1, \infty) .\end{cases}
$$

Define also $\gamma, \psi, \alpha$, and $\beta$ as in Example 2.2. We shall show that Theorem 2.7 can be applied for $f$, but Theorem 1.5 cannot be applied. Reviewing the proof of Example 2.2, $f$ is a $\gamma$-admissible mapping, $\alpha(0,0) \geq 1$ and if $\left\{x_{n}\right\}$ is a sequence in $X$ such that $\alpha\left(x_{n}, x_{n}\right) \geq 1$ for all $n \in \mathbb{N} \cup\{0\}$ and $x_{n} \rightarrow x$ as $n \rightarrow+\infty$, then $\gamma(x, x) \geq 1$. Let $\gamma(x, f x) \gamma(y, f y) \geq 1$. Then $x, y \in[0,1]$. Assume $y \geq x$. We get

$$
\begin{aligned}
\gamma(x, x) \gamma(y, y) \psi(d(f x, f y)) & =f y-f x+1 / 2 \\
& =\frac{1}{8}(y+x)(y-x)\left(y^{2}+x^{2}\right)+1 / 2 \\
& \leq \frac{1}{2}(y-x)+1 / 2 \\
& =\alpha(d(x, y))-\beta(d(x, y)) .
\end{aligned}
$$

Then the condition of Theorem 2.7 holds and $f$ has a fixed point. Clearly, the condition of Theorem 1.5 does not hold for this example.

Corollary 2.9 Let $(X, d, \preceq)$ be a partially ordered metric space such that $(X, d)$ is complete. Assume $f: X \rightarrow X$ and $\gamma: X \times X \rightarrow[0, \infty)$ are two mappings such that $f$ is a nondecreasing $\gamma$-admissible mapping. Assume that there exist $\psi \in \Psi, \alpha \in \Phi_{\alpha}$, and $\beta \in \Phi_{\beta}$ such that

$$
\psi(t)-\alpha(s)+\beta(s)>0 \quad \text { for all } t>0 \text { and } s=t \text { or } s=0
$$

and

$$
\gamma(x, f x) \gamma(y, f y) \gamma(x, x) \gamma(y, y) \psi(d(f x, f y)) \leq \alpha(d(x, y))-\beta(d(x, y))
$$

for all comparable $x, y \in X$. Suppose that either

(i) $f$ is continuous, or 
(ii) if a non-decreasing sequence $\left\{x_{n}\right\}$ is such that $x_{n} \rightarrow x$ as $n \rightarrow \infty, \gamma\left(x_{n}, x_{n}\right) \geq 1$, and $\gamma\left(x_{n}, f x_{n}\right) \geq 1$ for all $n$, then $\gamma(x, x) \geq 1, \gamma(x, f x) \geq 1$, and $x_{n} \preceq x$ for all $n \in \mathbb{N}$.

If there exists $x_{0} \in X$ such that $\alpha\left(x_{0}, x_{0}\right) \geq 1, \alpha\left(x_{0}, f x_{0}\right) \geq 1$, and $x_{0} \preceq f x_{0}$, then $f$ has a fixed point.

\section{Competing interests}

The authors declare that they have no competing interests.

\section{Authors' contributions}

All authors contributed equally to the writing of this paper. All authors read and approved the final manuscript.

\section{Author details}

'College of Mathematics and Information Science, Jiangxi Normal University, Nanchang, Jiangxi 330022, People's Republic of China. ${ }^{2}$ Department of Mathematics, Payame Noor University, P.O. Box 19395-3697, Tehran, Iran. ${ }^{3}$ Young Researchers and Elite Club, Rasht Branch, Islamic Azad University, Rasht, Iran. ${ }^{4}$ Faculty of Mechanical Engineering, University of Belgrade, Kraljice marije 16, Beograd, 11120, Serbia. ${ }^{5}$ Department of Applied Mathematics, Shri Vaishnav Institute of Technology and Science, Gram Baroli, Sanwer Road, Indore, MP 453331, India.

\section{Acknowledgements}

The authors are thankful to the referees for their valuable comments on this paper. Wei Long acknowledges support from the Research Project of Jiangxi Normal University (2012-114).

\section{Received: 18 December 2013 Accepted: 23 April 2014 Published: 13 May 2014}

\section{References}

1. Banach, S: Sur les opérations dans les ensembles abstraits et leur application aux équations intégrales. Fundam Math. 3, 133-181 (1922)

2. Berinde, $\mathrm{V}$, Vetro, F: Common fixed points of mappings satisfying implicit contractive conditions. Fixed Point Theory Appl. 2012, 105 (2012)

3. Chatterjea, SK: Fixed point theorem. C. R. Acad. Bulgare Sci. 25, 727-730 (1972)

4. Ćirić, LB: A generalization of Banach's contraction principle. Proc. Am. Math. Soc. 45, 267-273 (1974)

5. Damjanovic, B, Samet, B, Vetro, C: Common fixed point theorems for multi-valued maps. Acta Math. Sci. Ser. B, Engl. Ed. 32, 818-824 (2012)

6. Hadžić, O, Pap, E: Fixed Point Theory in Probabilistic Metric Spaces. Kluwer Academic, London (2001)

7. Kannan, R: Some results on fixed points. Bull. Calcutta Math. Soc. 60, 71-76 (1968)

8. Kannan, R: Some results on fixed points - II. Am. Math. Mon. 76, 405-408 (1969)

9. Matthews, SG: Partial metric topology. In: Proc. 8th Summer Conference on General Topology and Applications. Ann. New York Acad. Sci., vol. 728, pp. 183-197 (1994)

10. Mustafa, Z, Sims, B: A new approach to generalized metric spaces. J. Nonlinear Convex Anal. 7(2), $289-297$ (2006)

11. Nadler, SB Jr.: Multi-valued contraction mappings. Pac. J. Math. 30, 475-488 (1969)

12. Reich, S: Kannan's fixed point theorem. Boll. Unione Mat. Ital. 4, 1-11 (1971)

13. Suzuki, T: A generalized Banach contraction principle that characterizes metric completeness. Proc. Am. Math. Soc. $136,1861-1869(2008)$

14. Vetro, F: On approximating curves associated with nonexpansive mappings. Carpath. J. Math. 27, 142-147 (2011)

15. Dutta, PN, Choudhury, BS: A generalization of contraction principle in metric spaces. Fixed Point Theory Appl. 2008, Article ID 406368 (2008)

16. Abbas, M, Dorić, D: Common fixed point theorem for four mappings satisfying generalized weak contractive condition. Filomat 24(2), 1-10 (2010)

17. Dorić, D: Common fixed point for generalized $(\psi, \phi)$-weak contractions. Appl. Math. Lett. 22, 1896-1900 (2009)

18. Aydi, H, Karapinar, E, Samet, B: Remarks on some recent fixed point theorems. Fixed Point Theory Appl. 2012, 76 (2012)

19. Ran, ACM, Reurings, MCB: A fixed point theorem in partially ordered sets and some application to matrix equations. Proc. Am. Math. Soc. 132, 1435-1443 (2004)

20. Harjani, J, Sadarangani, K: Generalized contractions in partially ordered metric spaces and applications to ordinary differential equations. Nonlinear Anal. 72, 1188-1197 (2010)

21. Choudhury, BS, Kundu, A: $(\psi, \alpha, \beta)$-Weak contractions in partially ordered metric spaces. Appl. Math. Lett. 25, 6-10 (2012)

22. Karapinar, E, Salimi, P: Fixed point theorems via auxiliary functions. J. Appl. Math. 2012, Article ID 792174 (2012)

23. Samet, B, Vetro, C, Vetro, P: Fixed point theorems for $\alpha$ - $\psi$-contractive type mappings. Nonlinear Anal. 75, 2154-2165 (2012)

24. Salimi, P, Latif, A, Hussain, N: Modified $\alpha$ - $\psi$-contractive mappings with applications. Fixed Point Theory Appl. 2013, 151 (2013)

25. Mohammadi, B, Rezapour, S, Shahzad, N: Some results on fixed points of $\alpha$ - $\psi$-Ciric generalized multifunctions. Fixed Point Theory Appl. 2013, 24 (2013)

26. Asl, JH, Rezapour, S, Shahzad, N: On fixed points of $\alpha$ - $\psi$-contractive multifunctions. Fixed Point Theory Appl. 2012, 212 (2012)

27. Alikhani, H, Rezapour, S, Shahzad, N: Fixed points of a new type of contractive mappings and multifunctions. Filomat 27, 1315-1319 (2013) 
28. Hussain, N, Karapinar, E, Salimi, P, Akbar, F: $\alpha$-Admissible mappings and related fixed point theorems. J. Inequal. Appl. 2013, 114 (2013)

29. Geraghty, M: On contractive mappings. Proc. Am. Math. Soc. 40, 604-608 (1973)

30. Hussain, N, Karapinar, E, Salimi, P, Vetro, P: Fixed point results for $G^{m}$-Meir-Keeler contractive and $G$ - $(\alpha, \psi)$-Meir-Keeler contractive mappings. Fixed Point Theory Appl. 2013, 34 (2013)

31. Salimi, $\mathrm{P}$, Vetro, $\mathrm{C}$, Vetro, $\mathrm{P}$ : Fixed point theorems for twisted $(\alpha, \beta)-\psi$-contractive type mappings and applications. Filomat 27(4), 605-615 (2013)

32. Salimi, P, Vetro, C, Vetro, P: Some new fixed point results in non-Archimedean fuzzy metric spaces. Nonlinear Anal., Model. Control 18(3), 344-358 (2013)

33. Hussain, N, Kutbi, MA, Salimi, P: Best proximity point results for modified $\alpha$ - $\psi$-proximal rational contractions. Abstr. Appl. Anal. 2013, Article ID 927457 (2013)

34. Hussain, N, Salimi, P, Latif, A: Fixed point results for single and set-valued $\alpha-\eta$ - $\psi$-contractive mappings. Fixed Point Theory Appl. 2013, 212 (2013)

10.1186/1687-1812-2014-117

Cite this article as: Long et al.: Some new fixed point results in partial ordered metric spaces via admissible mappings. Fixed Point Theory and Applications 2014, 2014:117

\section{Submit your manuscript to a SpringerOpen ${ }^{\circ}$ journal and benefit from:}

- Convenient online submission

Rigorous peer review

- Immediate publication on acceptance

Open access: articles freely available online

- High visibility within the field

- Retaining the copyright to your article 